\title{
The effect of exercise counselling with feedback from a pedometer on fatigue in adult survivors of childhood cancer: a pilot study
}

\author{
Ria Blaauwbroek • Martijn J. Bouma • \\ Wemke Tuinier • Klaas H. Groenier • \\ Matthieu H. G. de Greef • Betty Meyboom- de Jong • \\ Willem A. Kamps • Aleida Postma
}

Received: 23 July 2008 / Accepted: 23 October 2008 / Published online: 18 November 2008

(C) The Author(s) 2008. This article is published with open access at Springerlink.com

\begin{abstract}
Objective The aim of this study was to evaluate the results of home-based exercise counselling with feedback from a pedometer on fatigue in adult survivors of childhood cancer. Patients Adult survivors of childhood cancer were recruited from the long-term follow-up clinic of the University Medical Centre Groningen, The Netherlands. A score of $70 \mathrm{~mm}$ on a visual analogue scale (scale, $0-100 \mathrm{~mm}$ ) for
\end{abstract}

R. Blaauwbroek · M. J. Bouma · W. Tuinier · W. A. Kamps •

A. Postma

University Medical Center Groningen, University of Groningen,

9700 RB Groningen, The Netherlands

R. Blaauwbroek · M. J. Bouma $\cdot$ W. Tuinier $\cdot$ W. A. Kamps $\cdot$

A. Postma

Department of Paediatrics, University Medical Center Groningen, 9700 RB Groningen, The Netherlands

R. Blaauwbroek $\cdot$ M. J. Bouma $\cdot$ W. Tuinier $\cdot$ W. A. Kamps

A. Postma

Division of Paediatric Oncology, University Medical Center Groningen, 9700 RB Groningen, The Netherlands

K. H. Groenier · B. Meyboom- de Jong

Department of General Practice,

University Medical Center Groningen,

Groningen, The Netherlands

M. H. G. de Greef

Institute of Human Movement Sciences, University of Groningen,

Groningen, The Netherlands

R. Blaauwbroek $(\bowtie)$

University Medical Center Groningen,

Hanzeplein 1, Postbus 30.001, 9700 RB Groningen,

The Netherlands

e-mail: r.blaauwbroek@bkk.umcg.nl fatigue was used as an inclusion criterion. Controls were recruited by the survivors among their healthy siblings or peers.

Methods During 10 weeks, the counselor encouraged the survivors to change their lifestyle and enhance daily physical activity such as walking, cycling, housekeeping and gardening. As a feedback to their physical activity, the daily number of steps of each survivor was measured by a pedometer and registered using an online step diary at the start of the programme and after 4 and 10 weeks. Fatigue was the primary outcome measure, assessed with the Checklist Individual Strength (CIS) at start (T0), 10 weeks (T10) and 36 weeks (T36). Thirty-three healthy agematched control persons were asked to complete the CIS. Results Out of 486 cancer survivors, 453 were interested and were asked to complete the VAS to measure fatigue; 67 out of 254 respondents met the inclusion criteria, 21 refused, 46 were enrolled and eight dropped out during the study. The mean scores on the CIS in the survivors at $\mathrm{T} 0$ was $81.42(\mathrm{SD} \pm 20.14)$ and at $\mathrm{T} 1062.62(\mathrm{SD} \pm 20.68)$, which was a significant improvement $(p<0.0005)$. At T36, the end of the study, the mean CIS score was 63.67 (SD \pm 23.12); this was a significant improvement compared with the mean CIS at the start $(p<0.0005)$. There was no significant difference in the mean CIS scores of the controls during the follow-up period.

Conclusion The stimulation of daily physical activity using exercise counselling and a pedometer over 10 weeks leads to a significant decrease in fatigue in adult survivors of childhood cancer, and this improvement lasts for at least 36 weeks.

Keywords Fatigue - Childhood cancer survivors · Exercise counselling $\cdot$ Pedometer 


\section{Introduction}

Fatigue can be defined as the perception of an unusual or debilitating sense of whole body tiredness, different from the usual sense of tiredness experienced by healthy individuals [14].

Fatigue is one of the late effects of (childhood) cancer that negatively affects quality of life $(\mathrm{QoL})$. The prevalence is unclear, and the aetiology is not well understood but probably multifactorial. Whatever the causes of fatigue in childhood cancer survivors are, those who experience fatigue need help.

A number of studies show different outcomes for the prevalence of fatigue in this particular population, varying from $5-40 \%[20,28,46]$. Other studies found no difference at all in fatigue between survivors and controls [19, 47]. Prevalence of fatigue in the general population ranges from $11 \%$ to $45 \%[6,21]$. The survivors in our study are young adults whose life goals include starting a family, a professional career, and the realisation of financial security. Fatigue is reflected in decreased QoL, especially when sufferers become too weary to fulfil the social roles that make life meaningful $[20,24]$.

Different types of interventions to decrease fatigue have been developed: exercise training, education, attentionrestoring activities and psychosocial techniques. In a randomised study, cognitive behaviour therapy showed a significant reduction of fatigue in severely fatigued diseasefree cancer patients [12]. There apparently is a relation between (lack of) exercise, QoL and fatigue [29]. In the general population, inactivity doubles the risk of fatigue [6]. Exercise programmes have shown positive results in the treatment of fatigue in cancer survivors [7, 5]. Dutch rehabilitation programmes for fatigued cancer survivors, such as 'Recovery \& Balance', combine exercise with psychological support and have shown positive results [13]. However, there are barriers to participate in these structured exercise programs. Participants in these programs are mostly survivors of adult cancer with a mean age of around 50 years, and young adult survivors of childhood cancer seldom participate [13]. Structured exercise programmes are time-consuming and especially young people-who often have jobs and raise a family - are often unable or unwilling to spend a lot of time on these programmes. Intervention meant to reduce fatigue should therefore be tailored to the survivors' needs, especially to the needs of young adult survivors of childhood cancer whose cancer treatment occurred far in the past. Studies of the exercise preferences of cancer survivors have shown that walking was their preferred daily physical activity, and they preferred exercise at home $[16,42,18]$. With this in mind, we designed an individualised exercise programme for enhancement of daily physical activity.
We hypothesised that severely fatigued childhood cancer survivors would be less likely to meet public health exercise guidelines (i.e. at least $150 \mathrm{~min}$ of moderate-to-vigorous exercise/week) and that enhanced daily activity could realise an improvement in fatigue. Therefore, the purpose of our study was to evaluate the effect of enhanced daily activity on fatigue in adult survivors of childhood cancer.

\section{Study subjects}

Adult survivors of childhood cancer were eligible when they are 18 years or older, 5 years or more post diagnosis, and participated in the long-term programme (LTFU) of the UMC Groningen, The Netherlands. They were sent information about the study by mail and invited to participate in this programme on fatigue. Exclusion criteria were as follows: using a wheelchair, contraindications for exercise or severe cognitive impairment. To exclude potential seasonal influence on outcome of the Checklist Individual Strength (CIS) and to compare the CIS results of the survivors to those of healthy persons, 33 healthy age-matched controls (sibs and/or friends) were approached by the survivors and, subsequently, the investigators to complete the CIS to measure fatigue at the same time as survivors.

The study was approved by the UMCG review board. Written informed consent was obtained from all survivors and controls.

All survivors who were interested in the study were invited to fill in a Visual Analogue Scale for chronic fatigue (VAS fatigue) and a Stage of Change (SOC) questionnaire. The VAS fatigue, which is a numerical measure ranging from 0 to 100 has been used to asses fatigue in cancer survivors. Survivors with a fatigue score of 70 or higher were classified as suffering from severe fatigue and showed a dramatic decrease in physical functioning [26, 27]. Therefore, we used a score of $70 \mathrm{~mm}$ or more on the VAS as an inclusion criterion. The SOC questionnaire was used to evaluate to what extend the survivors met public health exercise guidelines (i.e. at least $150 \mathrm{~min}$ of moderate-to-vigorous exercise/week). The SOC questionnaire is helpful for the counsellor to adjust his approach.

\section{Measuring instruments}

Visual analogue scale for fatigue

A Visual Analogue Scale for fatigue (VAS fatigue) is designed to measure the characteristic fatigue, which is believed to range across a continuum of values and cannot easily be measured directly. Operationally, the VAS is a horizontal line, $100 \mathrm{~mm}$ in length, anchored by word descriptors at each end. In our study, the descriptors ranged 
from 'not tired at all' to 'completely exhausted'. The patients were requested to mark on the line the point that they felt best represented their perception of their current state. The VAS fatigue score was then determined by measuring the distance in millimetres from the left-hand end of the line to the mark.

\section{The Stage of Change questionnaire}

The SOC is based on the Stages of Change Model developed by Prochaska and DiClemente [32]. This model suggests that people adjust their behaviour in five stages. People in stages 1-3 are sedentary. Those in stages 2 and 3 are more likely to change their physical activity behaviour. People in stages 1 and 2 will benefit most from a daily activity stimulation programme [2]. Those in stages 4 and 5 do already meet public health physical activity guidelines and need different advice in how to enhance daily physical activity compared to those in stages 1, 2 and 3 .

All survivors who were interested in taking part in the study were asked to complete the SOC questionnaire.

\section{Checklist individual strength (CIS)}

Fatigue was the primary outcome and it was measured with the CIS. The CIS is a validated 20-item questionnaire, that is designed to measure four aspects of fatigue that may have been experienced during the previous 2 weeks, i.e. severity of fatigue ( 8 items), concentration (5 items), motivation (4 items) and physical activity (3 items) [23]. Each item is scored on a 7-point Likert scale. The total score is the sum of the scores 1-7 on the 20 items (range 20-140). Norm scores are available for different patient groups and healthy people. Based on scores in healthy controls a score on the subscale 'fatigue severity' between 27 and 35 indicates an increased experience of fatigue. A score of 35 or higher indicates severe feelings of fatigue $[44,45]$.

\section{Pedometer (Yamax digiwalker SW-200 ${ }^{\circledR}$ )}

As Tudor Locke et al. have shown that a pedometer is helpful to provide feedback to those who use it, that it helps them to extend their daily activities and to set specific goals $[37,39]$, we used a pedometer to measure the number of daily steps. The Yamax digiwalker SW-200 ${ }^{\circledR}$, has been shown to be one of the most reliable pedometers [34, 40]. The instrument is worn on the belt or waistband and responds to vertical accelerations of the hip during walking. The non-ambulatory daily physical activities like swimming, cycling, weight lifting and so on are converted based on the intensity of this physical activity calculated in Metabolic Equivalents in minutes (METS min). For example: one minute cycling, swimming is about 150 steps [1]. The number of steps was registered in a step diary, either online or by posting their diaries, at start, in week 4 and week 10 (Fig. 1).

\section{Method}

The study design is summarised in Fig. 1

The counsellor (MB) encouraged participants to change their lifestyle and enhance daily physical activity such as walking, cycling, housekeeping and gardening. The pedometer was used as feedback instrument to give the survivors insight in their daily physical activity, to help them to extend their daily activities and to set new goals.

The counsellor was trained according to the $\mathrm{COACH}$ protocol (www.coachmethode.nl). This method is based on the Motivational Interviewing Technique created by Miller and Rollnick and the goal-setting theory developed by Locke and Lathem, both considered to be effective instruments for behavioural modification [22, 33].

At the start of the programme survivors were visited at home by the counsellor, who explained the use of the pedometer and the step diaries (Table 1). They were asked to complete the CIS questionnaire and to invite a sibling or peer of the same age as a control person for the CIS questionnaire. The controls completed the CIS on the same time as the survivors but did not use the pedometer. The survivors wore a pedometer during two weeks at start to assess steps at baseline and in week 4 and 10 during the study (Fig. 1). At the end of each day, participants had to record daily step counts and duration in minutes of other activities, in either an online step diary or a posted diary.

At three weeks, six weeks and nine weeks the counsellor phoned the survivors. The SOC results helped the counsellor to know in what stage the survivor is so his approach can be adjusted accordingly. Those in stages 2 and 3 are more likely to change their physical activity behaviour. Those in stages 4 and 5 do already meet public health physical activity guidelines and need different advice in how to enhance daily physical activity compared to those in stages 1,2 and 3.

At three weeks the use of the pedometer and the diary were evaluated and the results of the baseline measurement was discussed. Survivors were asked by how many steps they thought they could improve. Together with the counsellor, a new goal was set for the next appointment. All participants received a written summary of the telephone conversation and were asked to wear the pedometer again in week 4 , recording their steps in the diary. After six weeks the counsellor and the participant evaluated whether the goals set had been accomplished, and if not, the specific barriers were discussed. In some cases it was necessary to adjust the goal 


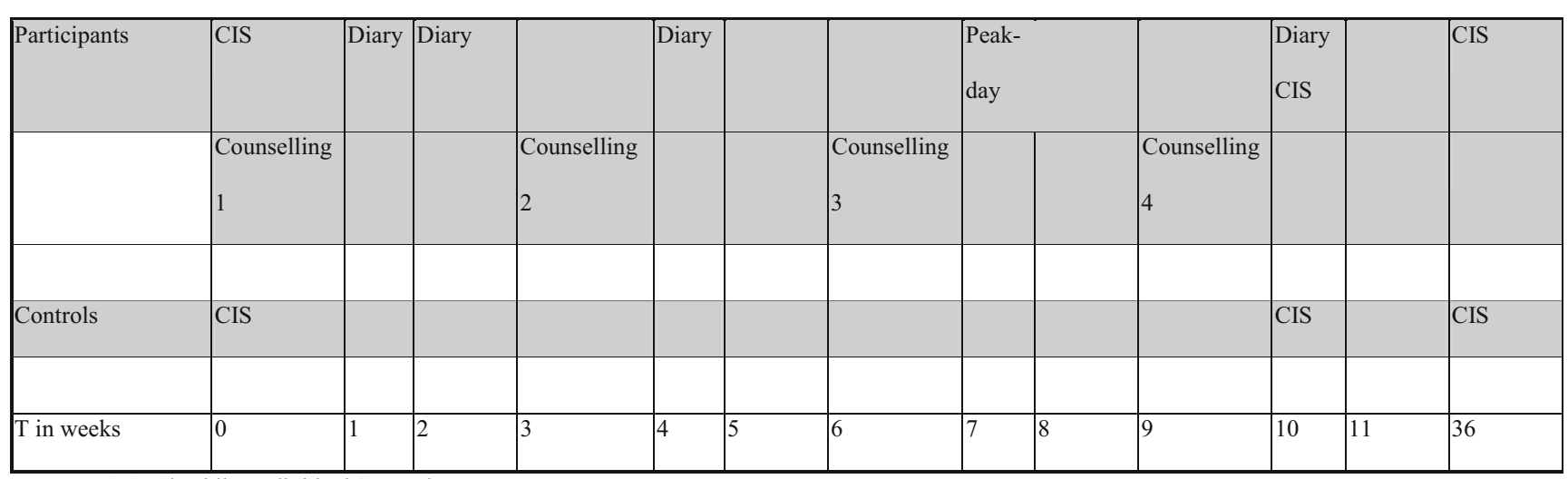

CIS: Checklist Individual Strength

Fig. 1 Study design. CIS Checklist Individual Strength

to a lower number of steps per day. Participants were asked to plan a 'peak day'. This was to be a day when circumstances were favourable (e.g. nice weather, shopping with a friend, etc.). On the peak day the survivor was supposed to take as many steps as possible. All survivors received a written summary of the telephone conversation and were asked to wear the pedometer on a peak day in week seven, recording the number of steps taken on this day in the step diary. After nine weeks the counsellor evaluated the 'peak day' and discussed with the survivors whether they thought it possible to adjust their goals to a higher number of steps per day. All participants received a written summary of the telephone conservation, and were asked to wear the pedometer in week ten, recording their steps in the step diary. Survivors and controls were asked to complete a CIS questionnaire at the end of the programme in week 10 and again in week 36 to asses if the assumed effect on fatigue would hold after termination of the counselling.

\section{Statistics}

A power analysis was calculated, with an alpha of 0.05 and a power of 0.80 . Assuming a correlation of 0.70 between successive measures and a standard deviation of 20 meant that if 50 survivors and controls participated, a decrease of nine points on the CIS (between baseline and end) could be detected in the participant group compared with controls.
We assumed that the CIS outcomes of the control group would not change. A general linear model for repeated measures (GLM) was used to compare the CIS results of survivors and controls over time (baseline, 10 weeks and 36 weeks). A 'repeated' contrast was used to investigate the significance of each measurement compared to the subsequent measurement. A general linear model for repeated measures was also used to study the change in daily physical activity (baseline, 3 weeks and 10 weeks) for the survivors. A linear regression analysis was used to analyse the relationship between the change in CIS score and the change in daily physical activity. A p-value less than 0.05 was considered significant. SPSS 15 was used to perform the analyses.

\section{Results}

Four hundred and eighty six survivors were eligible and were sent a letter to inform them of the study; initially those who replied (453/486), were sent the VAS and the SOC questionnaire. The response rate was 56\% (254/453). Sixtyseven survivors had a VAS score of $\geq 70 \mathrm{~mm}$, of these 67 qualifying survivors 21 refused participation for several reasons. Finally, 46 were enrolled in the study, but eight dropped out during the study. Descriptive characteristics of the survivors who entered the study at start are shown in Table 2. No statistically significant differences in age,

Table 1 Topics discussed by the counsellor at the start of the study

1 How the pedometer works

2 How to record the daily steps and other daily physical activity on the specially developed website or in the diary

3 An information leaflet on how to increase daily physical activity and develop a physically active lifestyle

4 Participants were asked to use a pedometer for 2 weeks maintaining their normal daily physical activities as usual, and record their steps in a diary on the website or by posted diaries. Baseline step monitoring was used to assess baseline daily physical activity

5 Participants were asked to complete a CIS questionnaire and to find a relative or friend who would also be willing to complete this questionnaire at three different moments during the study

6 Participants were shown how to keep in contact with the counsellor by e-mail or telephone 
cancer diagnosis and treatment between participants and non-participants were found. The median age at the study was 29 (range 18-61). Leukaemia was the most common diagnosis $(46.8 \%)$.

The Stage of Change questionnaire

Out of 453 survivors who were interested in the study, 251 childhood cancer survivors returned the SOC, $140(56 \%)$ survivors did not meet public health exercise guidelines (i. e. at least $150 \mathrm{~min}$ of moderate-to-vigorous exercise/week) [15]. Out of the 46 participants, $36(78 \%)$ did not meet public health exercise guidelines. The 46 participants were more likely (78\%) to be in one of the three lower scales of the SOC questionnaire than the total group of survivors who completed this questionnaire (56\%).

\section{Fatigue}

GLM analysis showed a significant interaction between time and group $(F=7.5, d f 2.58, p=0.001)$. The mean scores on the CIS in the survivors were $81.42 \pm 20.14$ at $\mathrm{T} 0$ and $62.62 \pm$ 20.86 at T10, which was a significant improvement $(F=19.7$, df $1.59, p<0.0005)$. At T36, the mean CIS score was $63.67 \pm$ 23.12, which was a significant improvement compared to the mean CIS at the start $(F=17.8, d f 1.59, p<0.0005)$. Controls had a mean score of $47.39 \pm 19.06$ at $\mathrm{T} 0$, of $46.18 \pm 17.70$ at $\mathrm{T} 10$ and of $42.57 \pm 17.40$ at $\mathrm{T} 36$.

Table 2 Characteristics of the participants

\begin{tabular}{|c|c|}
\hline & Participants $(n=46)$ \\
\hline Age (years) ${ }^{\mathrm{a}}$ & $29.8 \pm 8,6$ \\
\hline Age at diagnosis (years) ${ }^{\mathrm{a}}$ & $8.1 \pm 6.7$ \\
\hline Time since diagnosis ${ }^{\mathrm{a}}$ & $21.8 \pm 7.1$ \\
\hline Male gender ${ }^{\mathrm{b}}$ & $14(30.4)$ \\
\hline \multicolumn{2}{|l|}{ Diagnosis $^{\mathrm{b}}$} \\
\hline Leukemia & $22(46.8)$ \\
\hline Malignant lymphoma & $6(12.8)$ \\
\hline Bone tumour & $4(8.5)$ \\
\hline Soft tissue sarcoma & $3(6.4)$ \\
\hline Wilms' tumour & $1(2.1)$ \\
\hline Langerhans cell histiocytosis & $2(4.3)$ \\
\hline CNS tumour & $6(12.8)$ \\
\hline Other & $3(6.4)$ \\
\hline \multicolumn{2}{|l|}{ Treatment $^{\mathrm{b}}$} \\
\hline Chemotherapy only & $22(47.8)$ \\
\hline Surgery only & $2(4.4)$ \\
\hline Radiotherapy only & $0(0)$ \\
\hline Chemo and radiotherapy & $22(47.8)$ \\
\hline Cranial radiation & $12(26.1)$ \\
\hline
\end{tabular}

\footnotetext{
${ }^{\mathrm{a}}$ Median $\pm \mathrm{SD}$

${ }^{\mathrm{b}}$ Number (percentage)
}

This was significantly different $(F=29.7, d f 1.59, p<$ 0.0005) from the mean CIS scores at T0, T10 and T36 of the survivors. There was no statistically significant difference in the mean CIS scores of the controls during the study period (Fig. 2).

Daily physical activity (steps per day)

GLM analysis showed a significant increase in daily physical activity (steps per day) during the first 10 weeks $(F=16.7, d f$ $2.30, p<0.0005$ ). At T0, the mean number of daily steps in the participant group was $7.653 \pm 3.272$. After the first telephone session (T3) with the exercise counselor, there was an increase in the number of steps per day to $10.168 \pm$ 3.483 , which is an increase of $33 \%$. At T10, after the third telephone session, when participants were asked to adjust their goals, the number of daily steps increased to $11.803 \pm$ 3.695. This increase is statistically significant compared to the number of steps at $\mathrm{T} 0(F=32.0, d f 1.31, p<0.0005)$ and T3 $(F=10.4, d f 1.31, p=0.003)$. From the start until the end of the intervention (10 weeks), there was an increase in daily steps of $54 \%$ (Fig. 3). Although the number of daily steps increased during the study period, there was a low correlation of 0.12 between the increase in daily steps (T10 minus $\mathrm{T} 0$ ) and the decrease in fatigue (T10 minus $\mathrm{T} 0$ ).

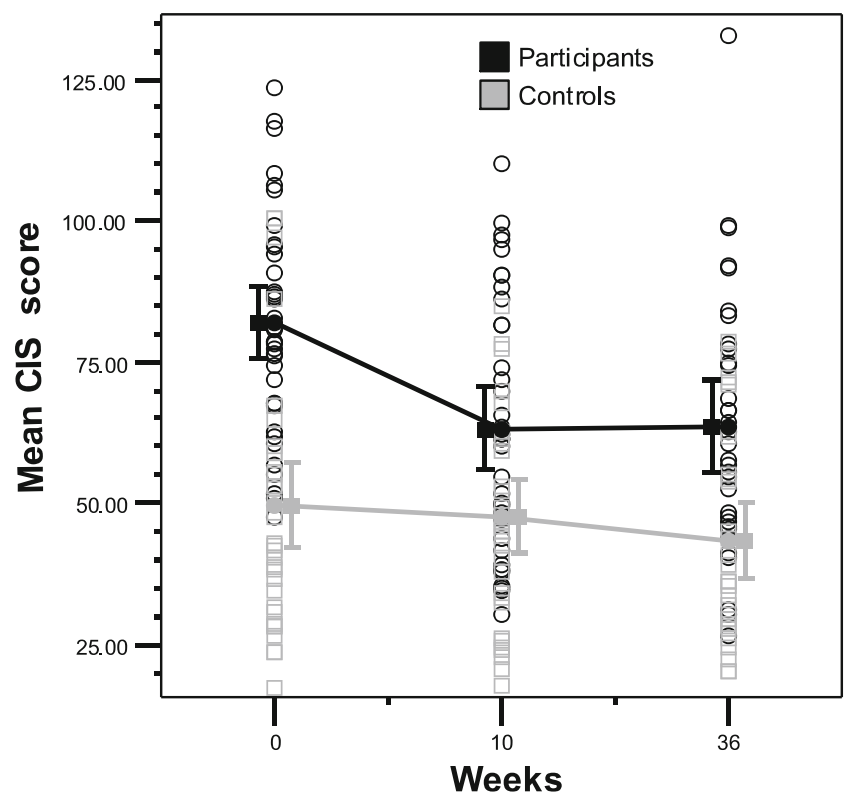

Fig. 2 Changes in CIS scores in survivors and controls during study period. CIS Checklist Individual Strength; lines connect mean CIS scores, vertical bars represent $95 \%$ CI. Mean CIS scores \pm SD of participants $(81.42 \pm 20.14$ at $\mathrm{T} 1 ; 62.62 \pm 20.86$ at $\mathrm{T} 10 ; 63.67 \pm 23.12$ at T 36) and controls $(47.39 \pm 19.06$ at $\mathrm{T} 1 ; 46.18 \pm 17.70$ at $\mathrm{T} 10 ; 42.57 \pm$ 17.40 at $\mathrm{T} 36)$ 


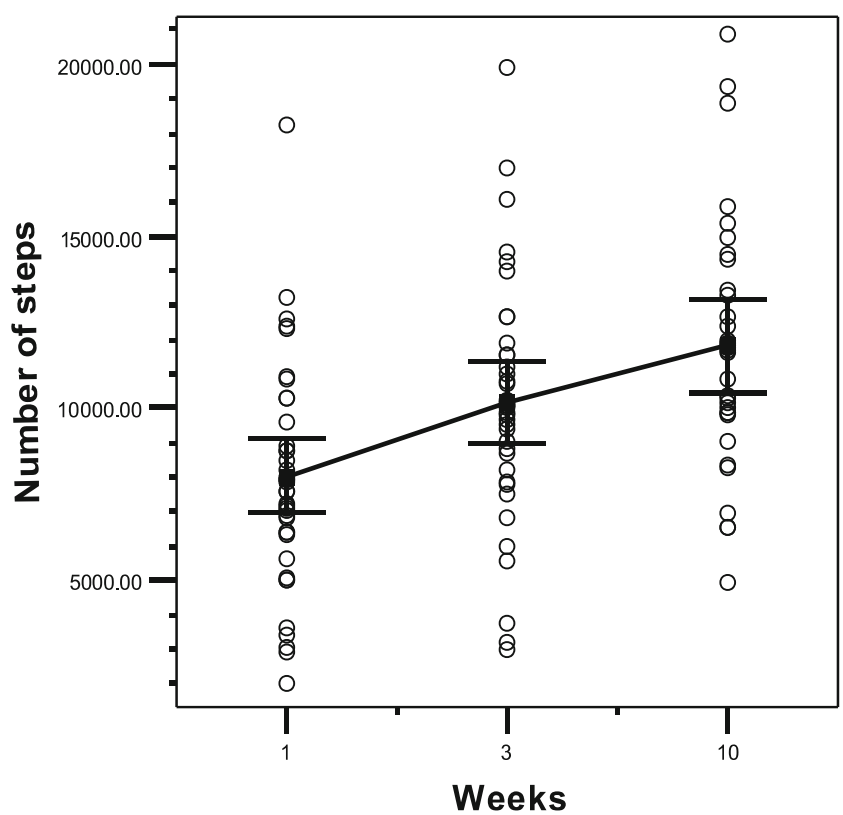

Fig. 3 Increase in number of steps of survivors during study period (lines connect means, error bars represent 95\% CI). Mean steps \pm SD of $\operatorname{survivors}(7.653 \pm 3.272$ at $\mathrm{T} 0 ; 10.168 \pm 3.483$ at $\mathrm{T} 3 ; 11.803 \pm 3.695$ at $\mathrm{T} 10)$

\section{Discussion}

In this study the effect of a home-based daily physical activity counselling programme-with feedback from a pedometer - on fatigue in adult survivors of childhood cancer was evaluated. It was shown that such a programme was effective in decreasing fatigue in adult survivors of childhood cancer during at least a 36 -week period. We found not only a statistically significant improvement in fatigue but also a statistically significant increase in daily physical activity, measured in steps per day by a pedometer. These results are in accordance with those of de Blok et al [4] who showed that the use of a pedometer in combination with exercise counselling is effective in increasing daily physical activity levels in COPD patients and of TudorLocke et al. [38] in patients with type 2 diabetes. Other studies conclude that a physical activity programme that adjusts lifestyle is as effective as a structured exercise programme in improving the daily physical activity of adults $[10,17]$. However, most studies have been done in breast cancer survivors $[7,43,31]$ and in patients who have received stem cell transplants $[5,9]$, whereas studies in childhood cancer survivors are limited [30]. We are not aware of other studies on the effectiveness of a physical activity counselling programme on fatigue in childhood cancer survivors.

Vallance et al. [41] reported that non-Hodgkin lymphoma survivors who met public health exercise guidelines had clinically and significantly higher QoL scores than survi- vors who did not meet these guidelines. In our study, 36 out of 46 participants $(78 \%)$ did not meet public health exercise guidelines (i.e. at least $150 \mathrm{~min}$ of moderate physical activity per week).

Fatigued survivors represent a high-risk group, as they report more depression and poorer QoL than non-fatigued survivors and their peers [25]. The aetiology of fatigue in (childhood) cancer survivors is still largely unknown. There is a relationship between depressive symptoms and fatigue $[11,19,25]$. The relationship is complex, as fatigue may be the result of a depressed mood while, at the same time, a severely fatigued person may also become depressed. Servaes et al. [36] showed that in a group of severely fatigued cancer survivors, only $19 \%$ could be considered to be clinically depressed and $14 \%$ were clinically anxious. Regular exercise, even a moderate walking exercise programme, has been shown to decrease anxiety and depression levels [35]. Whether the cause of fatigue in cancer survivors is related to depression or due to lack of physical activity, cancer survivors might benefit from regular exercise. For many years, physicians have recommended to cancer patients that they should rest and avoid physical effort because exercise could generate symptoms such as fatigue [8]. However, physical inactivity induces further muscular wasting and loss of cardiorespiratory fitness. This could explain the persistence of fatigue in some patients even years after the end of treatment.

When designing exercise programmes, it is useful that the preferences of individual survivors be taken into account; these preferences might change according to which stage of life they find themselves $[16,42]$.

Our study has several limitations. The sample size was small, and the response rate of $56 \%$ was moderate. This may have led to a biased selection of participants. The value of a pedometer as an instrument to assess exercise might be questioned, as it is not sensitive to non-ambulatory physical activities such as cycling, swimming and fitness training (weight lifting). However, a pedometer is cheap and easy to use and therefore highly suitable for daily use. Because eight persons dropped out during the study, we did not include the 50 survivors as we intended at start, but because the improvement in CIS scores was higher than expected, the study had still enough power. The study was not randomised, and controls did not use the pedometer.

\section{Conclusion}

The stimulation of physical activity using exercise counselling with feedback from a pedometer over 10 weeks leads to a statistically significant improvement in fatigue in adult survivors of childhood cancer, and this improvement lasts for at least 36 weeks. A home-based daily physical activity 
programme, compared to the existing structured exercise programmes in rehabilitation centres, is cheap, less timeconsuming and requires no special facilities. Therefore, this programme might be more suitable for young adults who are busy starting careers and planning to have a family. Randomised controlled studies with larger numbers of participants are needed to confirm our preliminary results. A longitudinal study is needed to examine long-term effects in terms of a decrease in fatigue.

Acknowledgements The study was financially supported by the Innovation Fund of the University Medical Center Groningen. All authors declare that the answer to the questions on your competing interest form are all "No" and therefore they have nothing to declare.

Contributors BMDJ, WAK, MHGDG and AP participated in the conception and design of the study and the critical revision of the report. $\mathrm{MB}, \mathrm{KHG}$ and $\mathrm{WT}$ participated in the data collection, data analysis and drafting of the report. MB, WT, BMDJ, WAK, MHGDG, KHG and AP approved the final report.

Open Access This article is distributed under the terms of the Creative Commons Attribution Noncommercial License which permits any noncommercial use, distribution, and reproduction in any medium, provided the original author(s) and source are credited.

\section{Reference}

1. Ainsworth BE, Haskell WL, Whitt MC, Irwin ML, Swartz AM, Strath SJ et al (2000) Compendium of physical activities: an update of activity codes and MET intensities. Med Sci Sports Exerc 32:S498-S504 doi:10.1097/00005768-200009001-00009

2. Ainsworth BE, Youmans CP (1993) Tools for physical activity counseling in medical practice. Obes Res 10(Suppl 1):69S-75S doi:10.1038/oby.2002.193

3. Bates DW, Schmitt W, Buchwald D, Ware NC, Lee J, Thoyer E et al (2006) Prevalence of fatigue and chronic fatigue syndrome in a primary care practice. Arch Intern Med 153:2759-2765 doi:10.1001/archinte.153.24.2759

4. de Blok BM, de Greef MH, ten Hacken NH, Sprenger SR, Postema K, Wempe JB (2006) The effects of a lifestyle physical activity counseling program with feedback of a pedometer during pulmonary rehabilitation in patients with COPD: a pilot study. Patient Educ Couns 61:48-55 doi:10.1016/j.pec.2005.02.005

5. Carlson LE, Smith D, Russell J, Fibich C, Whittaker T (2006) Individualized exercise program for the treatment of severe fatigue in patients after allogeneic hematopoietic stem-cell transplant: a pilot study. Bone Marrow Transplant 37:945-954 doi:10.1038/sj. bmt. 1705343

6. Chen MK (1986) The epidemiology of self-perceived fatigue among adults. Prev Med 15:74-81 doi:10.1016/0091-7435(86) 90037-X

7. Courneya KS, Mackey JR, Bell GJ, Jones LW, Field CJ, Fairey AS (2003) Randomized controlled trial of exercise training in postmenopausal breast cancer survivors: cardiopulmonary and quality of life outcomes. J Clin Oncol 21:1660-1668 doi:10.1200/ JCO.2003.04.093

8. Dimeo FC (2001) Effects of exercise on cancer-related fatigue. Cancer 92:1689-1693 doi:10.1002/1097-0142(20010915)92:6 $+<1689::$ AID-CNCR1498>3.0.CO;2-H
9. Dimeo FC, Tilmann MH, Bertz H, Kanz L, Mertelsmann R, Keul J (1997) Aerobic exercise in the rehabilitation of cancer patients after high dose chemotherapy and autologous peripheral stem cell transplantation. Cancer 79:1717-1722 doi:10.1002/(SICI)10970142(19970501)79:9<1717::AID-CNCR12>3.0.CO;2-0

10. Dunn AL, Andersen RE, Jakicic JM (1998) Lifestyle physical activity interventions. History, short- and long-term effects, and recommendations. Am J Prev Med 15:398-412 doi:10.1016/ S0749-3797(98)00084-1

11. Fobair P, Hoppe RT, Bloom J, Cox R, Varghese A, Spiegel D (1986) Psychosocial problems among survivors of Hodgkin's disease. J Clin Oncol 4:805-814

12. Gielissen MF, Verhagen S, Witjes F, Bleijenberg G (2006) Effects of cognitive behavior therapy in severely fatigued disease-free cancer patients compared with patients waiting for cognitive behavior therapy: a randomized controlled trial. J Clin Oncol 24:4882-4887 doi:10.1200/JCO.2006.06.8270

13. Gijsen BCM, Koppejan-Rensenbrink AG (2005) Herstel\&Balans. Groepsrevalidatie in de oncologie. Tijdschrift voor kanker 2005

14. Glaus A, Crow R, Hammond S (1996) A qualitative study to explore the concept of fatigue/tiredness in cancer patients and in healthy individuals. Eur J Cancer Care (Engl) 2(Suppl):8-23 doi:10.1111/j.1365-2354.1996.tb00247.x

15. Haskell WL, Lee IM, Pate RR, Powell KE, Blair SN, Franklin BA et al (2007) Physical activity and public health: updated recommendation for adults from the American College of Sports Medicine and the American Heart Association. Med Sci Sports Exerc 39:1423-1434 doi:10.1249/mss.0b013e3180616b27

16. Jones LW, Courneya KS (2002) Exercise counseling and programming preferences of cancer survivors. Cancer Pract 10:208-215 doi:10.1046/j.1523-5394.2002.104003.x

17. Kahn EB, Ramsey LT, Brownson RC, Heath GW, Howze EH, Powell KE, et al (2002) The effectiveness of interventions to increase physical activity. A systematic review. Am J Prev Med 22 (4)(Suppl):73-107. doi:10.1016/S0749-3797(02)00434-8

18. Karvinen KH, Courneya KS, Campbell KL, Pearcey RG, Dundas G, Capstick V et al (2006) Exercise preferences of endometrial cancer survivors: a population-based study. Cancer Nurs 29:259265 doi:10.1097/00002820-200607000-00001

19. Langeveld NE, Grootenhuis MA, Voute PA, de Haan RJ, Van den BC (2003) No excess fatigue in young adult survivors of childhood cancer. Eur J Cancer 39:204-214 doi:10.1016/S09598049(02)00629-9

20. Langeveld N, Ubbink M, Smets E (2000) 'I don't have any energy': The experience of fatigue in young adult survivors of childhood cancer. Eur J Oncol Nurs 4:20-28 doi:10.1054/ejon.1999.0063

21. Lewis G, Wessely S (1992) The epidemiology of fatigue: more questions than answers. J Epidemiol Community Health 46:92-97

22. Locke EA, Latham GP (2002) Building a practically useful theory of goal setting and task motivation. A 35-year odyssey. Am Psychol 57:705-717 doi:10.1037/0003-066X.57.9.705

23. Makowiec-Dabrowska T, Koszada-Wlodarczyk W (2006) The CIS20R Questionnaire and its suitability for prolonged fatigue studies. Med Press 57:335-345

24. Meeske KA, Patel SK, Palmer SN, Nelson MB, Parow AM (2007) Factors associated with health-related quality of life in pediatric cancer survivors. Pediatr Blood Cancer 49:298-305 doi:10.1002/pbc.20923

25. Meeske KA, Siegel SE, Globe DR, Mack WJ, Bernstein L (2005) Prevalence and correlates of fatigue in long-term survivors of childhood leukemia. J Clin Oncol 23:5501-5510 doi:10.1200/ JCO.2005.03.210

26. Mendoza TR, Wang XS, Cleeland CS, Morrissey M, Johnson BA, Wendt JK et al (1999) The rapid assessment of fatigue severity in cancer patients: use of the Brief Fatigue Inventory. Cancer 85:1186-1196 doi:10.1002/(SICI)1097-0142(19990301) 85:5<1186::AID-CNCR24>3.0.CO;2-N 
27. Mock V, Atkinson A, Barsevick A, Cella D, Cimprich B, Cleeland $\mathrm{C}$ et al (2000) NCCN practice guidelines for cancer-related fatigue. Oncology 14:151-161

28. Mulrooney DA, Ness KK, Neglia JP, Whitton JA, Green DM, Zeltzer LK et al (2008) Fatigue and sleep disturbance in adult survivors of childhood cancer: a report from the childhood cancer survivor study (CCSS). Sleep 31:271-281

29. Ness KK, Gurney JG, Zeltzer LK, Leisenring W, Mulrooney DA, Nathan PC et al (2008) The impact of limitations in physical, executive, and emotional function on health-related quality of life among adult survivors of childhood cancer: a report from the Childhood Cancer Survivor Study. Arch Phys Med Rehabil 2008:128-136 doi:10.1016/j.apmr.2007.08.123

30. Oldervoll LM, Kaasa S, Knobel H, Loge JH (2003) Exercise reduces fatigue in chronic fatigued Hodgkins disease survivorsresults from a pilot study. Eur J Cancer 39:57-63 doi:10.1016/ S0959-8049(02)00483-5

31. Pinto BM, Maruyama NC (1999) Exercise in the rehabilitation of breast cancer survivors. Psychooncology 8:191-206 doi:10.1002/ (SICI)1099-1611(199905/06)8:3<191::AID-PON355>3.0.CO;2-T

32. Prochaska JO, DiClemente CC (1992) Stages of change in the modification of problem behaviors. Prog Behav Modif 28:183-218

33. Rubak S, Sandbaek A, Lauritzen T, Christensen B (2005) Motivational interviewing: a systematic review and meta-analysis. Br J Gen Pract 55:305-312

34. Schneider PL, Crouter SE, Bassett DR (2004) Pedometer measures of free-living physical activity: comparison of 13 models. Med Sci Sports Exerc 36:331-335 doi:10.1249/01. MSS.0000113486.60548.E9

35. Segar ML, Katch VL, Roth RS, Garcia AW, Portner TI, Glickman SG et al (1998) The effect of aerobic exercise on self-esteem and depressive and anxiety symptoms among breast cancer survivors. Oncol Nurs Forum J 25:107-113

36. Servaes P, van der WS, Prins J, Verhagen S, Bleijenberg G (2001) Fatigue in disease-free cancer patients compared with fatigue in patients with chronic fatigue syndrome. Support Care Cancer 9:11-17 doi:10.1007/s005200000165

37. Tudor-Locke C, Bassett DR Jr (2004) How many steps/day are enough? Preliminary pedometer indices for public health. Sports Med 32:1-8 doi:10.2165/00007256-200434010-00001
38. Tudor-Locke C, Bell RC, Myers AM, Harris SB, Ecclestone NA, Lauzon $\mathrm{N}$ et al (2004) Controlled outcome evaluation of the First Step Program: a daily physical activity intervention for individuals with type II diabetes. Int J Obes Relat Metab Disord 28:113-119 doi: $10.1038 /$ sj.ijo.0802485

39. Tudor-Locke C, Burkett L, Reis JP, Ainsworth BE, Macera CA, Wilson DK (2005) How many days of pedometer monitoring predict weekly physical activity in adults? Prev Med 40:293-298 doi:10.1016/j.ypmed.2004.06.003

40. Tudor-Locke C, Sisson SB, Lee SM, Craig CL, Plotnikoff RC, Bauman A (2006) Evaluation of quality of commercial pedometers. Can J Public Health 97(Suppl 1):S10-S16

41. Vallance JK, Courneya KS, Jones LW, Reiman T (2005) Differences in quality of life between non-Hodgkin's lymphoma survivors meeting and not meeting public health exercise guidelines. Psychooncology 14:979-991 doi:10.1002/pon.910

42. Vallance JK, Courneya KS, Jones LW, Reiman T (2006) Exercise preferences among a population-based sample of non-Hodgkin's lymphoma survivors. Eur J Cancer Care (Engl) 15:34-43 doi:10.1111/j.1365-2354.2005.00617.x

43. Vallance JK, Courneya KS, Plotnikoff RC, Yasui Y, Mackey JR (2007) Randomized controlled trial of the effects of print materials and step pedometers on physical activity and quality of life in breast cancer survivors. J Clin Oncol 25:2352-2359 doi:10.1200/ JCO.2006.07.9988

44. Vercoulen JH (1999) De Checklist Individual Strength (CIS). Gedragstherapie 32:131-136

45. Vercoulen JH, Swanink CM, Fennis JF, Galama JM, Van Der Meer JW, Bleijenberg G (1994) Dimensional assessment of chronic fatigue syndrome. J Psychosom Res 38:383-392 doi:10.1016/0022-3999(94)90099-X

46. Wasserman AL, Thompson EI, Wilimas JA, Fairclough DL (1987) The psychological status of survivors of childhood/ adolescent Hodgkin's disease. Am J Dis Child 141:626-631

47. Zeltzer LK, Chen E, Weiss R, Guo MD, Robison LL, Meadows AT et al (1997) Comparison of psychologic outcome in adult survivors of childhood acute lymphoblastic leukemia versus sibling controls: a cooperative Children's Cancer Group and National Institutes of Health study. J Clin Oncol 15: 547-556 